ISSN 0103-5150

Fisioter. Mov., Curitiba, v. 28, n. 2, p. 259-268, Apr./June 2015

Licenciado sob uma Licença Creative Commons DOI: http://dx.doi.org.10.1590/0103-5150.028.002.A006

\title{
Energy expenditure and cardiovascular response to traumatic lower limb amputees' gait
}

\author{
Gasto energético e resposta cardiovascular da marcha \\ de amputados traumáticos de membros inferiores
}

\section{Marília Mendes do Nascimento Garcia ${ }^{[a]}$, Jorge Roberto Perrout de Lima ${ }^{[a]}$, José Dilermando Costa Junior ${ }^{[b]}$, Humberto Almeida Ottoni de Luna Freire ${ }^{[a]}$, Jaqueline de Paula Mazilão ${ }^{[\mathrm{a}]}$, Eduardo José Danza Vicente ${ }^{[\mathrm{a}] *}$}

[a] Universidade Federal de Juiz de Fora (UFJF), Juiz de Fora, MG, Brazil

[b] Universidade Federal do Rio de Janeiro (UFRJ), Rio de Janeiro, RJ, Brazil

\section{Abstract}

Introduction: Amputations cause functional, musculoskeletal and cardiovascular alterations and, the more proximal the amputation, the larger the alterations. Objectives: To observe the effect of using lower limb prosthetics and that of gait speed on heart rate (HR), blood pressure (BP), oxygen consumption $\left(\mathrm{VO}_{2}\right)$ and energy cost (EC) during gait in traumatic lower limbs amputees. Materials and methods: The sample was

\footnotetext{
* MMNG: MSc, e-mail: marimendes5@yahoo.com.br JRPL: PhD, e-mail: jorge.perrout@ufjf.edu.br JDCJ: PhD, e-mail: dilermandobras@yahoo.com.br HAOLF: grad., e-mail: betofisio85@yahoo.com.br JPM: grad., e-mail: jaquemazilaofisio@yahoo.com.br EJDV: PhD, e-mail: edujdv@yahoo.com.br
} 
composed of 30 men with unilateral amputations, 10 transfemoral and 10 transtibial, compared to 10 people with no amputations. All of them selected a pleasant walking speed (PWS) on the treadmill, and two other speeds were calculated, $20 \%$ above and $20 \%$ below the original one. The subjects walked for 10 minutes at each of the speeds and, in the last three minutes, the $\mathrm{VO}_{2}, \mathrm{HR}$, and $\mathrm{BP}$ were assessed. In order to compare variables between groups the variance was performed (ANOVA) followed by the Post Hoc Sheffé test ( $p<0.05)$. Results: The amputees selected lower values of PWS and had higher $\mathrm{HR}, \mathrm{BP}$, and $\mathrm{EC}, \mathrm{VO}_{2}$ during gait when compared to normal individuals. The transfemoral amputees had higher $\mathrm{VO}_{2}$ and $\mathrm{EC}$ compared to the transtibial ones. By analyzing the speed effect, it was observed that, although the $\mathrm{VO}_{2}$ did not increase with the increased speed, there was increased cardiovascular response and reduced EC. Conclusions: Traumatic lower limb amputees have higher energy expenditure and cardiovascular responses during gait and, at higher speeds, they become more economical, reducing the EC.

Keywords: Amputees. Gait. Energy metabolism. Blood pressure. Heart rate.

\section{Resumo}

Introdução: As amputações provocam alterações funcionais, musculoesqueléticas e cardiovasculares e, quanto mais proximal o nível da amputação, maiores essas alterações. Objetivos: Observar o efeito do uso de próteses de membros inferiores e da velocidade de marcha sobre a frequência cardíaca (FC), pressão arterial (PA), consumo de oxigênio $\left(\mathrm{VO}_{2}\right)$ e custo energético (CE) durante a marcha de amputados traumáticos de membros inferiores. Materiais e métodos: Foram estudados 30 indivíduos do sexo masculino, 20 possuíam amputações unilaterais traumáticas, sendo 10 transfemorais e 10 transtibiais, que foram comparados a 10 indivíduos sem amputações. Todos selecionaram uma velocidade de marcha agradável (VMA) na esteira rolante e foram calculadas e testadas outras duas, 20\% acima e 20\% abaixo da selecionada. Os indivíduos andaram por 10 minutos em cada velocidade $e$, nos três minutos finais, foram avaliados o $\mathrm{VO}_{2}$, a FC e a PA. Para comparação das variáveis entre os grupos foi realizada análise de variância (ANOVA), seguida do teste Post Hoc de Sheffé $(p<0,05)$. Resultados: Os amputados selecionaram menores valores de VMA e apresentaram maior $\mathrm{FC}, \mathrm{PA}, \mathrm{VO}_{2}$ e CE durante a marcha ao serem comparados aos indivíduos não amputados. Os transfemorais apresentaram maior $\mathrm{VO}_{2}$ e CE quando comparados aos transtibiais. Ao analisar o efeito velocidade, observou-se que, apesar do $\mathrm{VO}_{2}$ não ter aumentado com aumento da velocidade, houve aumento da resposta cardiovascular e redução do CE. Conclusões: Os amputados traumáticos de membros inferiores apresentam maior gasto energético e resposta cardiovascular durante a marcha e, em maiores velocidades, eles tornam-se mais econômicos, reduzindo o CE.

Palavras-chave: Amputados. Marcha. Metabolismo energético. Pressão arterial. Frequência cardíaca.

\section{Introduction}

Lower limb amputations cause functional $(1,2)$, musculoskeletal $(1,2)$ and cardiovascular changes $(3,4)$. The more proximal the amputation level, the greater these changes $(1,2,3)$. At rest, the amputees may have higher levels of catecholamines in blood, increased sympathetic nerve activity, increased blood pressure and increased heart rate (HR) when compared to normal individuals (3). Furthermore, amputees have muscle disorders, such as a reduced number and size of oxidative and increased glycolytic fibers (5), resulting in a predisposition to increased blood lactate levels (6).

The gait with the use of prosthesis causes higher energy expenditure when compared to the gait of normal individuals (1, 2, 7-11). During normal gait, the energy expenditure as a function of speed has the shape of a concave curve up, suggesting the existence of a more economical speed, which requires less oxygen consumption $\left(\mathrm{VO}_{2}\right)(1,3,12,13)$. In their daily walking, non-amputees adopt a so-called pleasant walking speed (PWS) which, in most cases, is close to the most economical speed $(1,12)$. In turn, lower 
limb amputees adopt a lower PWS, which is probably far from the economic speeds $(1,8,9,14)$.

The increased energy expenditure during the gait with prosthesis has been justified through the biomechanical changes resulting from the compensatory gait adopted by amputees $(8,9,15,16)$. Few studies have associated metabolic and cardiovascular variables during gait and evaluated the behavior of these variables during various walking speeds. Considering the functional (1), musculoskeletal (1) and cardiovascular $(3,4)$ changes occurring after amputation and the use of low running speeds by these individuals (1, $8,9,14)$, one can assume that the increased energy expenditure during gait with prosthesis would also be caused by cardiovascular changes and the adoption of lower and less economical running speeds. Therefore, the aim of this study was to observe the effect of wearing prostheses (transtibial and transfemoral) and gait speed on HR, blood pressure (BP), $\mathrm{VO}_{2}$ and energy cost (EC) during the gait of lower limb traumatic amputees.

\section{Materials and methods}

This study is characterized as a cross-sectional observational, controlled one, with a convenience sample of a paired selection of amputees and non amputated subjects in Juiz de Fora, MG, Brazil, and surrounding towns. Data collection occurred in the city of Juiz de Fora at the University Hospital of the Federal University of Juiz de Fora in 2008 and 2009.

\section{Ethics Committee}

According to Resolution No. 196/96 of the National Health Council (Conselho Nacional de Saúde, CNS), which regulates research involving human subjects, participation in this study was voluntary. All participants were informed about the nature and purpose of the study and signed the informed consent form (ICF). This study was submitted to the Research Ethics Committee of the Federal University of Juiz de Fora and approved under opinions 015/2007 and 159/2007. This study was registered in the Brazilian Registry of Clinical Trials (Registro Brasileiro de Ensaios Clínicos) under the identification RBR-4xrgxs.
Subjects

Thirty healthy and sedentary adult male subjects participated, 20 of them had unilateral traumatic lower limb amputations, 10 being transfemoral (Transfemoral Group) and 10 transtibial (Transtibial Group). These groups were compared with 10 individuals without amputations (Non-amputees Group).

In order to be part of the sample, the amputees should present amputation due to traumatic causes, have at least three years of amputation, be using the prosthetics for more than two years, walk without gait aid devices and use the prostheses with dynamic response $\mathrm{Sach}^{\mathrm{TM}}$ feet. The transfemoral subjects should have mechanical knees. All individuals in the amputation and control groups should be male, healthy, sedentary and without diagnosis of hypertension or cardiovascular disease and not use drugs that interfere in cardiovascular and hemodynamic variables. In addition, none of the subjects should have any pathology that could change gait quality, such as neuromuscular and joint disease involving the lower limbs.

\section{Experimental design}

The experimental protocol of this study occurred on three non-consecutive days. On the first day, the subjects underwent initial assessment, physical examination and familiarization with the treadmill. On the second day, all of them went through the PWS determination protocol and were instructed on the speeds that would be studied. On the last day, all subjects were assessed regarding the gait.

\section{Assessment and physical exam}

All subjects were initially assessed through medical history, physical therapy evaluation, measurement of blood pressure (BP) and HR at rest. To review these last two variables, the subjects should be at rest for at least 10 minutes in the supine position. Then all of them underwent anthropometric assessment, which evaluated body mass (kg), through the Asimed $^{\mathrm{TM}}$ scale, and height (m), through the Asimed ${ }^{\mathrm{TM}}$ stadiometer. The amputees were evaluated using the lower limb prosthesis. 
All assessments were performed at the University Hospital of the Federal University of Juiz de Fora (HU-UFJF), in the Dom Bosco unit, in the morning, to avoid interference of the circadian rhythm in the variables studied.

\section{Experimental procedure}

\section{Determination of the PWS}

One day before the completion of the experimental protocol, all subjects were familiarized with the Inbramed $^{\mathrm{TM}} 10200$ ATL treadmill for PWS selection. For this choice, the test started with the subject strolling at $1.5 \mathrm{~km} / \mathrm{h}$ and gradually increased the speed $(0.2$ $\mathrm{km} / \mathrm{h}$ every minute) until the subject reported that the previous speed was the most enjoyable one. Then the subject remained at that speed for two minutes to confirm that he/she correctly selected the PWS.

On the same day the PWS was selected, the volunteers adapted to the use of the treadmill, walking in gait speeds that would later be assessed. For that, a protocol with intervals in which all subjects walked for 10 minutes at each speed and rested 10 minutes was used.

\section{Gait assessment}

For gait assessment, an interval protocol on a Inbramed $^{\mathrm{TM}}$ treadmill, model $10200 \mathrm{ATL}$, using three gait speeds, was used: PWS, $20 \%$ above and $20 \%$ below this value, designated respectively for +20 PWS and -20 PWS. The order of application of each speed was randomly established.

The protocol started with a 15-minute rest in a sitting position, with the volunteer already making use of face masks for collection of the exhaled gases, heart rate monitor to collect HR and a cuff on the right arm for BP measurement. Later, a warm-up was performed for 2 minutes at $1.5 \mathrm{~km} / \mathrm{h}$, followed by a 10-minute walk at the first drawn speed and a 2-minute cooldown at $1.5 \mathrm{~km} / \mathrm{h}$. Then the subject rested for 15 minutes in a sitting position. The procedures were repeated with the other two speeds. During the final three minutes of rest and of each running speed, the exhaled gases and the HR were assessed and, in the final minute, BP was measured.

\section{Evaluation of oxygen consumption}

For the measurement of oxygen consumption during gait, indirect calorimetry was utilized (17), with the use of the VO2000 Medgraph ${ }^{\mathrm{TM}}$ gas analyzer and with the subjects wearing face masks. Before data collection, the equipment was calibrated according to the manufacturer's recommendations.

\section{Calculation energy cost}

The EC, which is the energy required to travel a meter, was calculated by multiplying the $\mathrm{VO}_{2}$ in liters per minute $(\mathrm{l} / \mathrm{min})$ by the caloric equivalent $\mathrm{O}_{2}$, given by kilocalorie per liter (kcal/l) (17). The value obtained was divided by the speed of travel in meters per minute $(\mathrm{m} / \mathrm{min})$, thereby obtaining the EC per meter value kilocalorie (kcal/m). The lower the value, the more economical the individual is.

\section{Evaluation of cardiovascular response}

The evaluation of the cardiovascular response was performed through HR and BP. The HR was recorded at the end of each speed and at rest by using the Polar $^{\mathrm{TM}}$ R810i heart rate monitor. BP measurement was performed by auscultation in the right upper limb using an anaeroid sphygmomanometer and a $\mathrm{BD}^{\mathrm{TM}}$ stethoscope, considering Korotkoff's stages I and IV to identify the systolic (SBP) and diastolic (DBP) blood pressure, respectively.

\section{Statistical analysis}

For the data analysis, the Shapiro-Wilk normality test was performed and it was observed that all variables were normally distributed. The results were transformed into text and tables by using the mean and standard deviation and figures, through average and a 95\% interval. For the comparison of the variables at rest a one-way variance analysis (ANOVA) was conducted, and for the comparison during the speeds analyzed a two-way ANOVA (speed and group factors) was conducted. Both analyses were followed by Sheffe's post hoc method. The $5 \%$ significance level was adopted. 


\section{Results}

When comparing the Non Amputee, Transtibial and Transfemoral groups, it was observed that there was no difference in relation to body weight, height and resting $\mathrm{BP}$, however, the Amputees had a higher resting HR when compared to the Non Amputees (Table 1).

During the gait, the group effect (Non Amputee, Transtibial and Transfemoral Group), speed and interaction (speed x group) were observed. Therefore, the results of this study will be presented as: amputation effect, which shows the comparison between the groups during gait, considering the 3 speeds studied, and the interaction effect, which evaluates each group compared to the increase in speeds and compared to the other groups.

\section{Amputation effect}

Table 2 describes speed, $\mathrm{BP}, \mathrm{HR}, \mathrm{VO}_{2}$ and $\mathrm{EC}$ values in each group, seen in the three speeds considered together. Regarding the Non Amputees, the Transtibial ones had lower running speed and higher values of $\mathrm{HR}, \mathrm{VO}_{2}$ and $\mathrm{EC}$, as the Transfemoral ones, besides the differences presented by the Transtibial ones, had higher SBP and DBP. When comparing the Transfemoral and Transtibial groups, there was a difference in the metabolic variables, and the Transfemoral ones had higher $\mathrm{VO}_{2}$ and $\mathrm{EC}$ values than the Transtibial ones.

\section{Interactions}

By analyzing the behavior of SBP and DBP at the three speeds analyzed, it was observed that only the Transfemoral group showed an increase of SBP when comparing the highest with the lowest gait speed studied (Figure 1).

As gait speed increased, an increase in HR was observed only in the amputee groups. The increase was higher in the Transfemoral group, which presented the HR difference at all speed increases. The Transtibial Group, however, only presented a HR difference when comparing the values obtained at higher and at the lower speeds. When analyzing the $\mathrm{VO}_{2}$ behavior in the three speeds studied, there was no significant difference from the increased speed in any group (Figure 2).

In relation to the $\mathrm{EC}$, a reduction of these values was observed as gait speed increased in the Transfemoral and Transtibial groups. This reduction was also found in the Non Amputees group. Nevertheless, it only occurred by comparing the values of EC in highest and in the lowest gait speed (Figure 3).

Table 1 - Characterization of the sample at rest (mean \pm standard deviation)

\begin{tabular}{lccc}
\hline & $\begin{array}{c}\text { Non amputees } \\
(\mathbf{n}=\mathbf{1 0})\end{array}$ & $\begin{array}{c}\text { Transtibial } \\
(\mathbf{n}=\mathbf{1 0})\end{array}$ & $\begin{array}{c}\text { Transfemoral } \\
(\mathbf{n}=\mathbf{1 0})\end{array}$ \\
\cline { 3 - 4 } Age (years) & $42.20 \pm 4.54$ & $39.30 \pm 3.59$ & $42.20 \pm 4.54$ \\
Body mass $(\mathrm{kg})$ & $76.20 \pm 6.06$ & $79.00 \pm 3.85$ & $79.40 \pm 4.42$ \\
Height $(\mathrm{m})$ & $1.73 \pm 0.10$ & $1.74 \pm 0.07$ & $1.75 \pm 0.06$ \\
SBP at rest $(\mathrm{mmHg})$ & $121.30 \pm 6.79$ & $123.50 \pm 8.18$ & $126.40 \pm 5.31$ \\
DBP at rest $(\mathrm{mmHg})$ & $78.70 \pm 5.73$ & $84.10 \pm 5.64$ & $84.60 \pm 6.86$ \\
HR at rest $(\mathrm{bpm})$ & $82.20 \pm 9.00$ & $91.60 \pm 2.87^{*}$ & $92.10 \pm 4.72^{*}$ \\
\hline
\end{tabular}

Note: *Significant difference from the Non Amputees group. 
Table 2 - Mean and standard deviation of speed, systolic blood pressure (SBP), diastolic blood pressure (DBP), heart rate $(\mathrm{HR})$, oxygen consumption $\left(\mathrm{VO}_{2}\right)$ and energy cost $(\mathrm{EC})$ for the three walking speeds analyzed and compared between groups

\begin{tabular}{lccc}
\hline & & \multicolumn{2}{c}{ Amputees } \\
\cline { 3 - 4 } & $\begin{array}{c}\text { Non amputees } \\
(\mathrm{n}=10)\end{array}$ & $\begin{array}{c}\text { Transtibial } \\
(\mathrm{n}=10)\end{array}$ & $\begin{array}{c}\text { Transfemoral } \\
(\mathrm{n}=10)\end{array}$ \\
\hline Speed $(\mathrm{km} / \mathrm{h})$ & $3.07 \pm 0.58$ & $2.44 \pm 0.57^{*}$ & $2.20 \pm 0.38^{*}$ \\
SBP $(\mathrm{mmHg})$ & $127.70 \pm 8.28$ & $132.13 \pm 8.01$ & $137.33 \pm 7.01^{*}$ \\
DBP $(\mathrm{mmHg})$ & $85.83 \pm 12.16$ & $89.86 \pm 5.69$ & $94.73 \pm 2.80^{*}$ \\
HR $(\mathrm{bpm})$ & $94.13 \pm 11.29$ & $119.00 \pm 19.61^{*}$ & $124.60 \pm 14.02^{*}$ \\
V02 $(\mathrm{l} / \mathrm{min})$ & $0.87 \pm 0.16$ & $1.25 \pm 0.24^{*}$ & $1.59 \pm 0.19^{*} \#$ \\
EC $(\mathrm{Kcal} / \mathrm{m})$ & $0.08 \pm 0.01$ & $0.15 \pm 0.04^{*}$ & $0.21 \pm 0.04^{*} \#$ \\
\hline
\end{tabular}

Note: * Significant difference from the Non Amputees group. \#Significant difference from the Transtibial Amputees group.
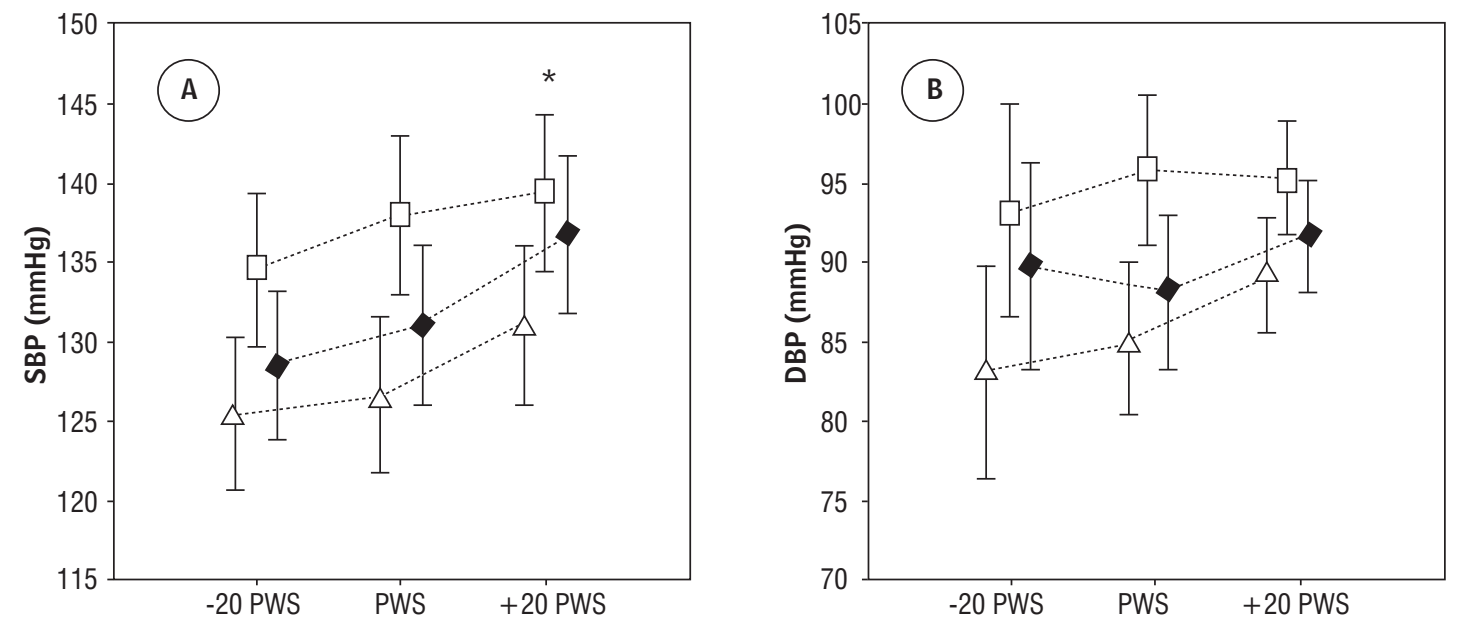

$\triangle-N A \quad \square-T F A$

-TTA

Figure 1 - Intragroup comparison with regards to systolic blood pressure (SBP) and diastolic blood pressure (DBP), respectively. Graphics A and B, with the increase of gait speed (-20 PWS; PWS and +20 PWS), reached by the Non Amputee (NA), Transtibial Amputee (TTA) and Transfemoral Amputee (TFA) groups. Data are presented as mean and with a $95 \%$ confidence interval

Note: * Significant difference regarding the -20 CGC. 

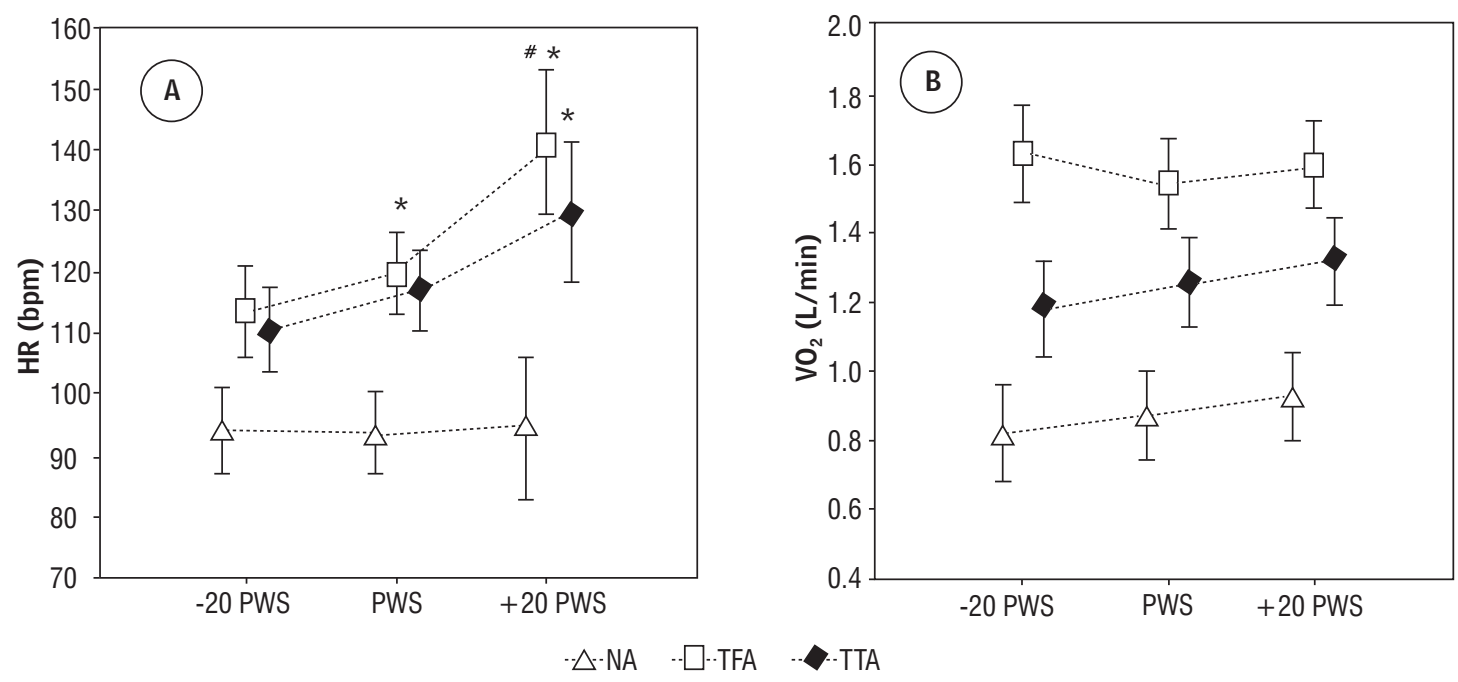

Figure 2 - Intragroup comparison regarding heart rate $(\mathrm{HR})$ and oxygen consumption $\left(\mathrm{VO}_{2}\right)$, graphs A and $\mathrm{B}$, respectively, with the increase of gait speed (-20 PWS; PWS and +20 PWS), reached by the Non Amputee (NA), Transtibial Amputee (TTA) and Transfemoral Amputee (TFA) groups. Data are presented as mean and with a $95 \%$ confidence interval Note: *Significant difference regarding the -20 PWS. \#Significant difference regarding the PWS.

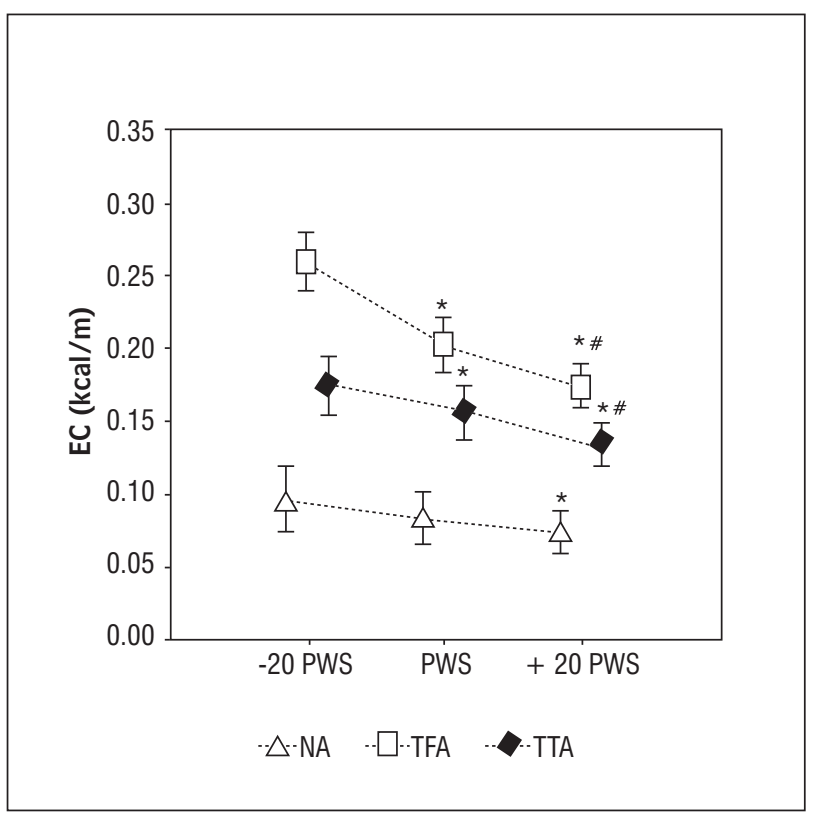

Figure 3 - Intragroup comparison regarding energy cost (EC) with increasing gait speed (-20 PWS; PWS and +20 PWS), reached by the Non Amputee (NA), Transtibial Amputee (TTA) and Transfemoral Amputee (TFA) groups. Data are presented as mean and $95 \%$ confidence interval

Note: *Significant difference regarding the -20 PWS. \#Significant difference regarding the PWS.

\section{Discussion}

The main findings of this study were: 1) At rest, the amputees had similar AP and higher HR than the non amputees; 2) The amputees, even walking at lower speeds, presented higher SBP, DBP, $\mathrm{HR}, \mathrm{VO}_{2}$ and EC. The more proximal the level of amputation, the lower the gait speed, the higher the $\mathrm{VO}_{2}$ and the EC; and 3) the increase of gait speed causes an increase in HR in amputees without, however, increasing the $\mathrm{VO}_{2}$ due to the improvement of the EC.

\section{Amputation effect during rest}

During rest, the amputees had a higher HR and the same AP when compared to the group of Non Amputees. Corroborating this study, there is evidence that amputees have high levels of HR, which occur due to increased sympathetic nerve activity and hemodynamic changes in those individuals (3). To justify these results, there is an association with increased serum levels of catecholamines due to the compression of the fitting on the stump and vascular alterations resulting from the amputation $(3,4,18)$. 
Regarding BP values at rest, our results were different from those found in the literature, which report the presence of high blood pressure and predisposition or presence of systemic arterial hypertension (SAP) in traumatic lower limb amputees $(3,19)$. These results were probably different due to the fact that our volunteers were younger and that we adopted the presence of hypertension and/or cardiovascular disease as exclusion criteria.

Although the amputees assessed do not present increased BP, they have high HR levels at rest, generating a propensity to develop hypertension and increased cardiovascular risk. There is evidence that the increase in HR, the plasma catecholamine levels (19) and the hemodynamic changes in traumatic lower limb amputees $(3,19)$, in the long term, predispose them to increased BP, development of SAH $(18,19,20)$ and increased risk of developing cardiovascular disease and mortality $(3,4,18,19,20)$.

\section{The effect of amputation on gait}

The amputees in this study adopted a lower PWS when compared to the non amputees and, the more proximal amputation, the lower the speed adopted. These results are in agreement with those reported in the literature $(1,21,22)$, which states that the amputees adopt lower gait speeds in order to reduce energy expenditure $(1,8,9,14)$ acquire greater dynamic stability during walk $(16,22,23)$ and reduce the risk of falls in this activity. The transfemoral amputees, due to the loss of the physiological knee, have higher biomechanical changes during gait causing them to walk more slowly $(2,8,24)$.

Although the amputees adopt a lower PWS, they present a higher cardiovascular and metabolic response and, the more proximal the amputation, the greater the changes. Similar results regarding HR during gait were also found in other studies $(24,25,26)$. However, in relation to the AP there were no studies that could be compared with ours. The increased heart rate and blood pressure can probably be justified by the sympathetic nervous activity present in these individuals, seen in traumatic amputees at rest using lower limb prosthesis (19).

During gait, even adopting a slower PWS, the amputees had a higher $\mathrm{VO}_{2}$ and EC. These results were also found in other studies that evaluated the energy expenditure in amputees $(1,7,8,10)$, who claim that the largest biomechanical changes during gait and the loss of muscle mass and inserts present in these individuals lead to an overload other muscle groups, thus increasing the EC for walking $(1,7,8,10,27)$. The transfemoral amputees, when compared to the Transtibial ones had higher $\mathrm{VO}_{2}$ due to higher biomechanical changes induced by the level of amputation, the loss of the physiological knee and the greater muscle involvement $(1,2,8)$.

\section{Speed effect on gait}

The increase in gait speed caused the amputees' HR increase, however, there are no studies analyzing the effect of gait speed on HR in amputees which could be compared with our results. It is believed that the HR increase in amputees can be justified by the attempt to increase cardiac output in higher gait speeds. Kurdibaylo et al. (18), when assessing the HR behavior during maximum exercise, observed that by increasing exercise intensity, the amputees, especially the transfemoral ones, showed a slight increase in the end systolic volume and, to compensate, the HR increased sharply in order to maintain cardiac output. It is believed that during gait, a similar mechanism may have occurred.

When assessing the behavior of the metabolic variables during gait, it was found that there was no increase in $\mathrm{VO}_{2}$ at higher speeds due to the EC improvement, especially in the amputees. There is evidence that, at higher gait speeds, there is a reduction of the biomechanical changes in lower limb amputees due to a reduced oscillation of the center of body mass, increased pendulum movement and ease of implementation of gait phases, especially in the transfemoral amputees $(8,10,22,28)$, which probably explains the reduction of EC values at higher speeds.

During normal gait, there is a speed range, close to the CGC, which is more economical $(1,9,12,17,26)$, and which also occurs with lower limb amputees (9), since by increasing gait speed, there is a decreased caloric intake per meter walked. However, in this study, the most pleasant speed was not the most economical one, which was also found by Jaegers et al. (26) and, because only three gait speeds were assessed, it was not possible to find the most economical speed range for these individuals. 
Applications in rehabilitation

Through this study one can see the importance of performing cardiac rehabilitation programs in amputees to reduce metabolic and cardiovascular impact during gait and to prevent the development of hypertension and cardiovascular disease. It is suggested that, prior to cardiovascular programs in amputees, ergometric tests should be conducted using a stationary bicycle or upper limb cycle ergometer (29) to assist in the prescription of the HR zone training and to verify whether subjects have cardiovascular limitations for the exercise (30). Another suggestion is to do training at various walking speeds with monitoring of $\mathrm{HR}$ and BP during exercise, since these variables showed different behaviors from those in normal individuals.

Finally, it should be noted that the amputees assessed in this study had traumatic amputations. There is evidence that amputated subjects, due to vascular etiology, have higher cardiovascular and metabolic changes resulting from the underlying disease they have $(1,31)$. Thus, assessments before prescribing and performing aerobic activities in vascular lower limb amputees become necessary.

\section{Limitations of the study}

In the present study few walking speeds were studied, making it impossible to find the most economical speed range for the amputee. By adopting the self-selected speed choice protocol, the subjects chose low PWS values and hence, when calculating the other two speeds studied, they represent the same exercise intensity.

\section{Conclusion}

From this study it can be concluded that the traumatic transfemoral and transtibial amputees have higher energy expenditure, increased cardiovascular response and are less economical while walking with prosthesis when compared to normal individuals. The transfemoral amputees have a higher metabolic and cardiovascular impact when walking, when compared to the transtibial amputees. At higher speeds, despite the increased cardiovascular impact, the amputees' gait becomes more economical, with reduction of the EC. From the results found, the recommendation for cardiovascular rehabilitation programs for traumatic lower limb amputees is justified.

\section{Acknowledgments}

The authors thank the Research Foundation of the State of Minas Gerais of (Fundação de Amparo à Pesquisa do Estado de Minas de Gerais, FAPEMIG) for the financial support.

\section{References}

1. Waters RL, Mulroy S. The energy expenditure of normal and pathologic gait. Gait Posture. 1999;9(3):207-31.

2. Waters RL, Perry J, Antonelli D, Hislop H. Energy cost of walking of amputees: the influence of level of amputation. J Bone Joint Surg Am. 1976;58(1):42-6.

3. Naschitz JE, Lenger R. Why traumatic leg amputees are at increased risk for cardiovascular diseases. QJM. 2008;101(4):251-9.

4. Nallegowda M, LeeE, Brandstater M, Kartono AB, Kumar G, Foster GP. Amputation and cardiac comorbidity: analysis of severity of cardiac risk. 2012;4(9):657-66.

5. Fraisse N, Martinet N, Kpadonou TJ, Paysant J, Blum A, Andre JM. [Muscles of the below-knee amputees]. Ann Readapt Med Phys. 2008;51(3):218-27.

6. Santos JJA, Cervelini R, Martinazzo JM, Ellert F. Qualidade de vida e lactacidemia durante a prova de caminhada de seis minutos em portadores de insuficiência cardíaca. Arq Ciências Saúde Unipar. 2008;12(1):9-17.

7. Schmalz T, Blumentritt S, Jarasch R. Energy expenditure and biomechanical characteristics of lower limb amputee gait: the influence of prosthetic alignment and different prosthetic components. Gait Posture. 2002; 16(3):255-63.

8. Detrembleur C, Vanmarsenille J-M, Cuyper FD, Dierick F. Relationship between energy cost, gait speed, vertical displacement of centre of body mass and efficiency of pendulum-like mechanism in unilateral amputee gait. Gait Posture. 2005;21(3):333-40.

9. Genin J, Bastien G, Franck B, Detrembleur C, Willems P. Effect of speed on the energy cost of walking in unilateral traumatic lower limb amputees. Eur J Appl Physiol. 2008;103(6):655-63. 
10. Traballesi M, Porcacchia P, Averna T, Brunelli S. Energy cost of walking measurements in subjects with lower limb amputations: a comparison study between floor and treadmill test. Gait Posture. 2008;27(1):70-5.

11. Lin-Chan S, Nielsen D, Shurr D, Saltzman C. Physiological responses to multiple speed treadmill walking for Syme vs. transtibial amputation-a case report. Disabil Rehabil. 2003;25(23):1333-8.

12. Rose J, Gamble JG, organizadores. Marcha: teoria e prática da locomoção humana. 3. ed. Rio de Janeiro: Guanabara Koogan; 2007.

13. Dutra LN, Damasceno OC, Silva AC, Vianna JM, Novo Junior JM, Lima JRP. Estimativa do gasto energético da caminhada. Rev Bras Med Esporte. 2007;13(5):321-6.

14. Houdijk H, Pollmann E, Groenewold M, Wiggerts $H$, Polomski W. The energy cost for the step-to-step transition in amputee walking. Gait Posture. 2009;30(1): $35-40$.

15. Sagawa Y, Turcot K, Armand S, Thevenon A, Vuillerme N, Watelain E. Biomechanics and physiological parameters during gait in lower-limb amputees: a systematic review. Gait Posture. 2011;33(4):511-26.

16. Gailey R, Allen K, Castles J, Kucharik J, Roeder M. Review of secondary physical conditions associated with lower-limb amputation and long-term prosthesis use. J Rehabil Res Dev. 2008;45(1):15-29.

17. McArdle WD, Katch FI, Katch VL. Fisiologia do exercício: energia, nutrição e desempenho humano. Rio de Janeiro: Guanabara Koogan; 2008.

18. Kurdibaylo SF. Cardiorespiratory status and movement capabilities in adults with limb amputation. J Rehabil Res Dev. 1994;31(3):222-35.

19. Grubeck-Loebenstein B, Korn A, Waldhäusl W. The role of adrenergic mechanisms in the blood pressure regulation of leg-amputees. Basic Res Cardiol. 1981;76(3):267-75.

20. Frugoli BA, Guion KW, Joyner BA, McMillan JL. Cardiovascular disease risk factors in an amputee population. J Prosthet Orthot. 2000;12(3):80-7.

21. Boonstra AM, Fidler V, Eisma WH. Walking speed of normal subjects and amputees: aspects of validity of gait analysis. Prosthet Orthot Int. 1993;17(2):78-82.
22. Goujon-Pillet H, Sapin E, Fode P, Lavaste F. Three-dimensional motions of trunk and pelvis during transfemoral amputee gait. Arch Phys Med Rehabil. 2008; 89(1):87-94.

23. Nolan L, Wit A, Dudzinski K, Lees A, Lake M, Wychowanski M. Adjustments in gait symmetry with walking speed in trans-femoral and trans-tibial amputees. Gait Posture. 2003;17(2):142-51.

24. Crouse S, Lessard C, Rhodes J, Lowe R. Oxygen consumption and cardiac response of short-leg and longleg prosthetic ambulation in a patient with bilateral above-knee amputation: comparisons with able-bodied men. Arch Phys Med Rehabil. 1990;71(5):313-7.

25. Hoffman MD, Sheldahl LM, Buley KJ, Sandford PR. Physiological comparison of walking among bilateral above-knee amputee and able-bodied subjects, and a model to account for the differences in metabolic cost. Arch Phys Med Rehabil. 1997;78(4):385-92.

26. Jaegers SM, Vos LD, Rispens P, Hof AL. The relationship between comfortable and most metabolically efficient walking speed in persons with unilateral above-knee amputation. Arch Phys Med Rehabil. 1993;74(5):521-5.

27. Yeung LF, Leung AKL, Zhang M, Lee WCC. Long-distance walking effects on trans-tibial amputees compensatory gait patterns and implications on prosthetic designs and training. Gait Posture. 2012;35(2):328-33.

28. Schmid M, Beltrami G, Zambarbieri D, Verni G. Centre of pressure displacements in trans-femoral amputees during gait. Gait Posture. 2005;21(3):255-62.

29. Haddad S. Ergometria de membros superiores. Um método importante na avaliação cardiocirculatória ao exercício. Arq Bras Cardiol. 1997;69(3):189-93.

30. Meneghelo R, Araújo C, Stein R, Mastrocolla L, Albuquerque P, Serra S, et al. III Diretrizes sobre teste ergométrico. Arq Bras Cardiol. 2010;95(5 supl. 1):1-26.

31. Varu VN, Hogg ME, Kibbe MR. Critical limb ischemia. J Vasc Surg. 2010;51(1):230-41.

Received: 08/02/2012

Recebido: 02/08/2012

Approved: 01/30/2015

Aprovado: 30/01/2015 